\title{
Developmental Endocrinology
}

National Cancer Institute

\section{Source}

National Cancer Institute. Developmental Endocrinology. NCI Thesaurus. Code C18735.

The branch of endocrinology concerned with changes in the metabolism and physiology

of hormonal secretions that take place between fertilization and maturity. 